\title{
VALORACIÓN MONETARIA DE LOS BENEFICIOS QUE PUEDE RENDIR UN USO ÓPTIMO DEL SUELO EN LA MICROCUENCA MONTEADENTRO DEL RIO PAMPLONITA, PAMPLONA, N. DE S.
}

Nathalie Hernández Pérez *

\footnotetext{
* Profesora Departamento de Economía Universidad de Pamplona. Agradecimientos a la asesoría del profesor Arturo Martínez Bolívar.
} 


\section{VALORACIÓN MONETARIA DE LOS BENEFICIOS QUE PUEDE RENDIR UN USO ÓPTIMO DEL SUELO EN LA MICROCUENCA MONTEADENTRO DEL RIO PAMPLONITA, PAMPLONA, N. DE S.}

\begin{abstract}
RESUMEN
El suelo de la microcuenca de Monteadentro es usado en la actualidad para siembra y ganadería, estas actividades productivas provocan externalidades negativas a la población de Pamplona, puesto que afectan el balance hídrico provocando una disminución en la producción y calidad de agua.

Valorar monetariamente los beneficios sociales y ambientales por la calidad y mayor producción de agua con un uso diferente al que actualmente se le da al suelo en la microcuenca de Monteadentro del nacimiento del Río Pamplonita, fue el objetivo de este estudio, el cual se llevo a cabo por medio del método de Valoración Contingente (MVC).

Para elaborar el instrumento se realizo una descripción del área del estudio según los usos actuales del suelo y la externalidades que estos producen y se especificaron los servicios ambientales del uso productor y protector del agua. El $77.89 \%$ de la población, presento disposición a pagar por los servicios ambientales (producción y calidad de agua) y un $46 \%$ dijo estar dispuesto a pagar una suma de más a la anterior porque valora los demás servicios ambientales.
\end{abstract}

Palabras Claves: Método de valoración contingente, servicios ambientales, disposición a pagar, Áreas estratégicas.

\begin{abstract}
The soil of Monteadentro's microbasin is used nowadays for the sowing and ranching(cattle), these productive activities provoke externalidades denials the population of Pamplona, since they affect the water balance provoking a decrease in the production and water quality.
\end{abstract}

To value monetariamente the social and environmental benefits for the quality and major production of water with a use different from the one that nowadays gives himself(itself) him to the soil in Monteadentro's microbasin of the birth of the Rio Pamplonita, it was the aim(lens) of this study, which I carry out by means of the method of Valuation Quota (MVQ).

To elaborate the survey I realize a description of the area of the study according to the current uses of the soil and the externalidades that these produce and there were specified the environmental services of the producing and protective use of the water. $77.89 \%$ of the population, they present disposition(regulation) to pay for the environmental services (production and water quality) and $46 \%$ said to be ready to pay a sum of more to the previous one because it values other environmental services.

Keywords: contingent valuation, Environmental services, Disposition to pay, Strategic areas.

\section{Face IssN 1794-9920}

Recepción: Enero de 2010

Revisión: Junio de 2010

Aceptación: Junio de 2010 


\section{INTRODUCCIÓN}

La quebrada Monteadentro nace a 3200 m.s.n.m. en la vereda que lleva el mismo nombre al Sur Oriente del municipio de Pamplona, Norte de Santander (figura 1. color rosado). Esta microcuenca tiene su origen en la naciente denominada El Chorro de las Pavas y recorre 5.2 kilómetros hasta el encuentro con la quebrada El Volcán, con la que conforma el Río Pamplonita. (En la figura 1., en color turquesa, vereda Alto Grande, donde nace quebrada el Volcán).

Figura 1. Mapa veredal Pamplona.

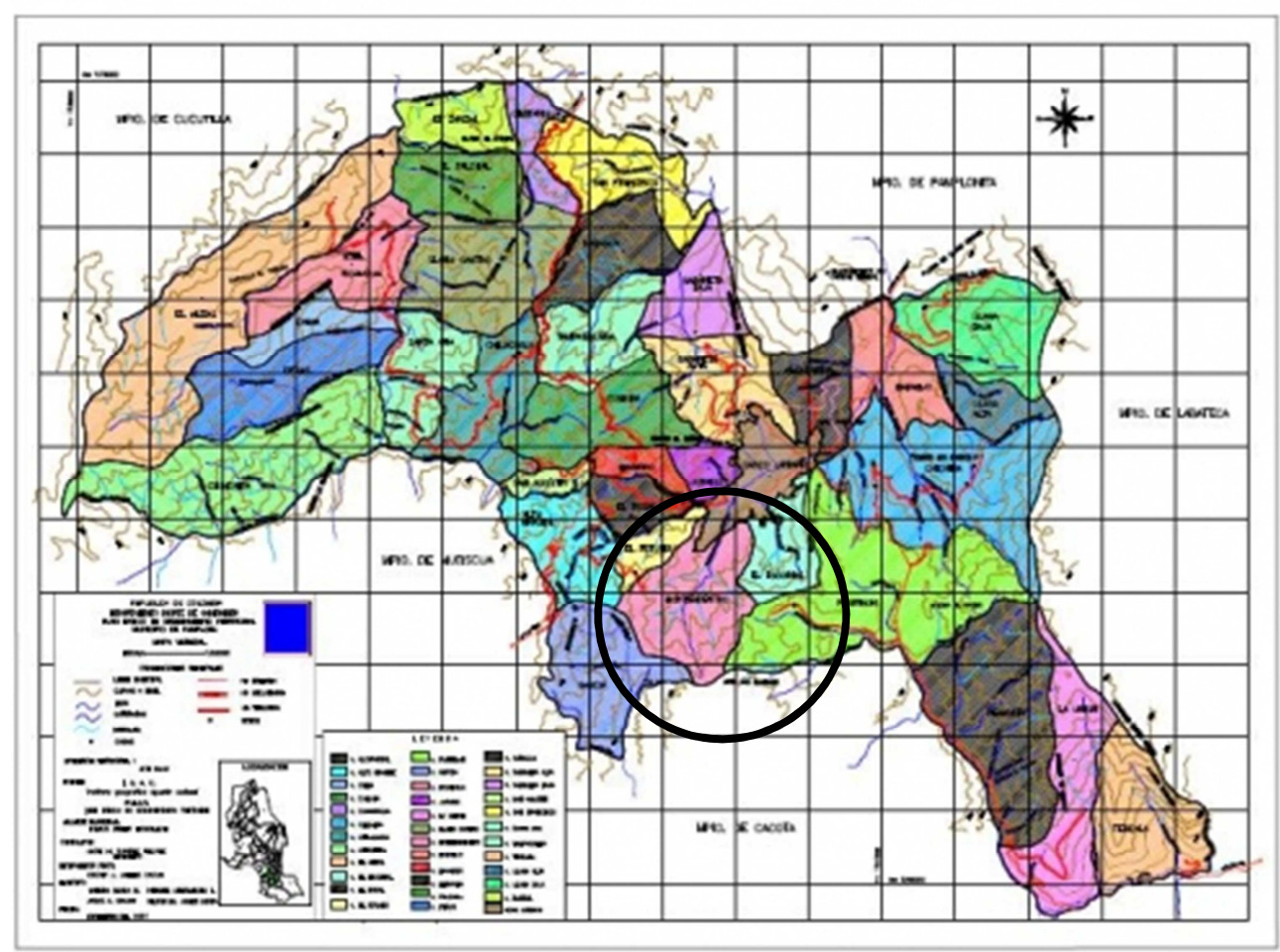

Fuente: Pagina Web Alcaldía de Pamplona.

El área aproximada de la microcuenca es de $9.8 \mathrm{Km} 2$ y su perímetro es de $15.8 \mathrm{Km}$. Los afluentes principales son las quebradas Teorama, Cepeda, Cerrajones, Piñuelal y La Corcova. La forma es oval redonda y el relieve de esta microcuenca es quebrado, razón por la que los drenajes son cortos y en su mayoría poco ramificados, la microcuenca de Monteadentro tiene pendientes altas en sus nacimientos y bajas en su parte final. 
El clima de la microcuenca Monteadentro es frío subhúmedo, el relieve secundario contribuye a formar microclimas que dividen la microcuenca en: un $10 \%$ como bosque húmedo montano bajo, correspondiente a ecosistemas de páramo y un $90 \%$ es bosque seco montano bajo. En el primero las temperaturas oscilan ente 6 y $12^{\circ} \mathrm{C}$, mientras que el segundo toma temperaturas entre 12 y $17^{\circ} \mathrm{C}$, con variaciones ligeras de $2^{\circ} \mathrm{C}$ en ambos casos en los meses de junio y enero principalmente.

El caudal promedio de la microcuenca es de 109.7L/seg., del cual se capta para los usuarios $93.24 \mathrm{~L} / \mathrm{seg}$., correspondiente a un $85 \%$ y se deja el $15 \%$ restante como caudal ecológico, lo que corresponde a 16,46L/seg. De los 93.24L/seg., EMPOPAMPLONA toma 80L/seg en la captación de Cariongo construida en 1960 con una capacidad de $150 \mathrm{~L} / \mathrm{seg}$. Estos $80 \mathrm{~L} / \mathrm{seg}$. contribuyen a suplir el 50\% de la demanda de sus 11723 usuarios $^{1}$ que consumen $200 \mathrm{~L} / \mathrm{d}$ promedio en el área urbana y $150 \mathrm{~L} / \mathrm{d}$ en el área rural. Se puede decir que la contribución de esta quebrada es la mayor de las cuatro existentes, puesto que la captación del Rosal o Volcán provee 50 L/seg.(31,25\%), El Mono 15 L/seg.(9.37\%) y Potreritos 15L/seg. $(9.37 \%)^{2}$.

Según MARQUEZ (2007) la demanda de agua que hacen los pamploneses de la microcuenca de Monteadentro se distribuye así: uso domestico (3.189.552 M3/AÑ), uso pecuario (8.734 M3/AÑO) y uso agrícola (1.836.325 M3/AÑ) para un total de 5.034.612 M3/AÑO. Sin embargo en el año 2005 CORPONOR otorgó una concesión a EMPOPAMPLONA S.A.E.S.P. de 2.928.117, lo que indica que existe un $125.79 \%$ de escasez del recurso hídrico según el Plan Básico de Ordenamiento Territorial (PBOT). Pamplona 2001 y un $73.16 \%$ según los cálculos realizados con la reglamentación de CORPONOR del 2005. Este índice de escasez es alto siguiendo los parámetros del IDEAM, puesto que es mayor de $50^{3}$.

El balance hídrico posibilita la determinación de la disponibilidad hídrica natural y el comportamiento de la oferta, sea esta superficial o subterránea. En el balance hídrico hecho para la consultoría del Plan Maestro de Acueducto EMPOPAMPLONA S.A.E.S.P. a partir de los datos que provee el IDEAM se encontró un déficit para ocho meses. Según MARQUEZ (2006), el déficit se dio en los meses de enero, febrero, marzo, mayo, junio, julio, agosto y septiembre, y menciono que las condiciones disminuyen las posibilidades de almacenamiento en un 66.7\%.Las entradas de agua se hacen en forma de precipitación (lluvia) y las salidas por medio de la evotranspiración

\footnotetext{
${ }^{1}$ Fuente: Oficina de Facturación EMPOMPLONA. La distribución de usuarios es: Estrato 1 (1844), Estrato 2 (3607), Estrato 3 (4010), Estrato 4 (1489), comercial (649), Especial (34) y Oficial (79)

2 CORPONOR (2004). Proyecto de distribución de caudales dentro del proceso de reglamentación del uso del agua en las microcuencas el Volcán y Monteadentro a partir de sus nacimientos en su paso por las veredas el totumo, alto grande, el rosal, navarro, jurado, barrio el Zulia y Monteadentro del municipio de Pamplona hasta su confluencia con la cuenca del río Pamplonita.

${ }^{3}$ Clasificación del IDEAM para el índice de escasez: NS: No significativo (IE>1), MI: (IE: 1-10), ME: medio (IE: 11-20), MA: Medio Alto (IE:21-50) y AL: Alto (IE: > 50)
} 
real (evaporación desde la superficie del suelo, transpiración de las plantas, intercepción, variación de la humedad del suelo y de la humedad en la vegetación), el otro factor de salida son las corrientes de agua superficial que representa la producción hídrica, esta fluye en un área determinada, subterránea o proviene de un acuífero ${ }^{4}$.

Tabla 1. balance hídrico global del municipio de Pamplona.

\begin{tabular}{|l|l|l|l|l|l|l|l|l|l|l|l|l|l|}
\hline MES & ENE & FEB & MAR & ABR & MAY & JUN & JUL & AGO & SEP & OCT & NOV & DIC & TOTAL \\
\hline Precipitación $(\mathrm{mm})$ & 31 & 40 & 68 & 95 & 87 & 67 & 53 & 60 & 102 & 134 & 101 & 48 & 886 \\
\hline Evaporación $(\mathrm{mm})$ & 96 & 88 & 96 & 86 & 102 & 96 & 104 & 106 & 105 & 92 & 88 & 92 & 1151 \\
\hline $\begin{array}{l}\text { Evo transpiración } \\
(\mathrm{mm})\end{array}$ & 42 & 40 & 68 & 86 & 95 & 67 & 53 & 60 & 102 & 92 & 88 & 92 & 885 \\
\hline Almacenamiento $(\mathrm{mm})$ & 0 & 0 & 0 & 8 & 0 & 0 & 0 & & 0 & 42 & 55 & 11 & 116 \\
\hline Déficit $(\mathrm{mm})$ & 54 & 48 & 28 & 0 & 7 & 29 & 51 & 46 & 3 & 0 & 0 & 0 & 266 \\
\hline Exceso $(\mathrm{mm})$ & 0 & 0 & 0 & 0 & 0 & 0 & 0 & 0 & 0 & 0 & 0 & 0 & 0 \\
\hline
\end{tabular}

Fuente: Plan maestro de acueducto 2006

La calidad de agua según el estudio hecho por la Universidad Francisco de Paula Santander que llega hasta la captación de Cariongo es 4, presentando la misma calidad de aguas abajo donde el río ya ha pasado por el área urbana debido a la contaminación que recibe por parte de la población y malas prácticas de cultivo, descargas de aguas residuales domesticas y lavado de arenas. Cabe comparar que la calidad de agua de la captación de la microcuenca el Volcán, comprada como área estratégica es categoría II ${ }^{5}$.

El agua es un recurso común del cual menos del 3\% del porcentaje total de agua de la tierra es dulce 6 . Como consecuencia de las propiedades que tiene un recurso común, este presenta mayor deterioro por no tener un valor. El agua hace parte de las necesidades básicas del ser humano por lo que la mejora de la disponibilidad y calidad de los recursos hídricos del planeta es una de las Metas del Desarrollo del Milenio pactada en la cumbre de Johannesburgo 2002 (MARTINEZ y KOSOY. 2007). Debido a la problemática de la ciudad de Pamplona con respecto a la producción y calidad del recurso hídrico mencionada anteriormente y teniendo en cuenta como lo mencionaron en la declaración del Segundo Congreso Mundial de Paramos? "el agua debe garantizarse de manera equitativa en cantidad y calidad para la satisfacción de las necesidades básicas”. Según las proyecciones hechas para otorgar la concesión de aguas a EMPOPAMPLONA 8 , tomando en cuenta la demanda promedio de agua por habitante equivalente a 167.8 1/hab/día, para el año 2010 existiría un déficit de

\footnotetext{
${ }^{4}$ Hypergeo. Balance Hídrico.2004

${ }^{5}$ Las categorías van de menor a mayor, siendo la categoría I la mejor y IV la de mayor contaminación.

${ }^{6}$ SACHS, Jefrey. 2008. Economía para un planeta abarrotado. Primera edición. Bogotá D.C.

${ }^{7}$ II Congreso Mundial de Paramos. PARAMUNDI. Declaración de Cuenca sobre el Manejo Integral de los recursos Hídricos (2009)

8 Resolución \# 0011 del 9 de marzo del 2004. "Por el cual se otorga una concesión de aguas"
} 
910m3/día, puesto que el caudal mínimo de los afluentes es de $10.781 \mathrm{~m} 3 /$ día y la demanda sería de $11.691 \mathrm{~m} 3 /$ día, sin embargo, la captación actual es de 12.096m3/ día, y estas proyecciones se hicieron, con base en una población de 69.661 habitantes. El que hoy exista capacidad de suplir la demanda y que el crecimiento de la población no sea el proyectado, no significa que no se este cerca del tope de la capacidad, por tanto, se hace necesario tomar medidas en la actualidad, para poder suplir la demanda futura.

A pesar de que la población de Pamplona es la principal afectada con la perdida del bosque en las microcuencas, aproximadamente 1.500.000 habitantes de la ciudad de Cúcuta, Pamplona, Los Patios y municipios aledaños se benefician del recurso hídrico proveniente de estas microcuencas, razón por la que el municipio de Pamplona junto con CORPONOR y con la ayuda de estudiantes de Ingeniería forestal de la Universidad Distrital francisco José de Caldas llevaron a cabo el Plan de administración y manejo ambiental para el área estratégica parte alta de la microcuenca el Volcán municipio de Pamplona, el área para la que se diseño el plan consta de 603,5 hectáreas, que fueron compradas con la financiación de CORPONOR y en la actualidad se encuentran en conservación, protección y recuperación. ${ }^{9}$

Con el Plan mencionado anteriormente se mejora la cantidad y calidad de agua pero teniendo en cuenta el crecimiento futuro de la población y factores externos como el cambio climático, la medida tomada sigue siendo ineficiente. En la actualidad de la microcuenca el Volcán se pueden tomar 60 litros por segundo, mientras que de la microcuenca de Monteadentro que sigue siendo terreno de propiedad privada se toman 80 litros por segundo, esta microcuenca en condiciones no óptimas para la producción y calidad de agua contribuye en mayor proporción a suplir la demanda de agua, se puede inferir que sí las condiciones de la microcuenca el Volcán mejoraron en cuanto a la producción y calidad de agua, la capacidad de la Microcuenca de Monteadentro puede ser mayor. Para mejorar la producción y calidad de agua, se requiere comprar 480 hectáreas ubicadas en la Microcuenca de Monteadentro, que se encuentran divididas en 5 predios y tienen un costo de 590 millones de pesos $^{10}$.

Con el fin de proporcionar información para la toma de decisiones sobre el gasto publico para mejorar las condiciones actuales de oferta de agua en el Municipio de Pamplona. El objetivo del estudio es valorar monetariamente los beneficios sociales y ambientales por la calidad y mayor producción de agua con un uso diferente al que actualmente se le da al suelo en la microcuenca de Monteadentro del nacimiento del Río Pamplonita. Para ello se realiza una descripción del área de estudio según los usos actuales del suelo de la microcuenca y las externalidades que ellos producen, además de

\footnotetext{
${ }_{9}$ Plan de administración y manejo ambiental para el área estratégica parte alta de la microcuenca el Volcán municipio de Pamplona. Bogotá, 2005, Universidad Distrital Francisco José de Caldas-CORPONOR. proyecto curricular de ingeniería forestal.

${ }^{10}$ Información suministrada por Luis Andrés Ocampo, personal de EMPOPAMPLONA E.S.P.S.A.
} 
una especificación de los beneficios ambientales del uso del suelo productor y protector de agua en la microcuenca de Monteadentro.

\section{Usos actuales del suelo y sus externalidades}

Para el año 2001 ${ }^{11}$, la vereda de Monteadentro se encontraba habitada por 412 personas en 82 viviendas, sin embargo para el año 2006, fecha en que se realizo la reglamentación para la captación en los diferentes predios, se encontraron 111 usuarios, de los cuales el $45.1 \%{ }^{12}$ son propietarios y el restante $54.9 \% 0^{13}$ viven en condición de trabajo como arrendados.

La vivienda de los pobladores está construida en ladrillo y tapia, con techos en teja, zinc y eternit principalmente y pisos de tierra seguido por el uso de cemento. En estas viviendas solo el 18.3\% cuentan con baño, lo que contribuye a que la falta de un pozo séptico lleve los desechos a las quebradas contaminando las aguas que hay antes y después de la captación de Cariongo.

En estas casas se cocina con leña $(75.6 \%)$ y gas $(24.4 \%)$, esto quiere decir que la mayoría de la población esta expuesta a los efectos nocivos que produce cocinar con leña como contraer cáncer de pulmón, bronquitis, tuberculosis, asma, pulmonía y otras enfermedades respiratorias. Según la Organización Mundial de la Salud cada veinte segundos una persona muere como resultado de estas condiciones, conocidas con el nombre de Polución del Medio Ambiente Interior (WHO, 2005). La leña para consumo se extrae de los árboles de cada finca, los árboles como el arrayán, aliso y tuno, son de manejo sostenible, pues mientras se retiren solo las ramas, estas volverán a retoñar, sí el retiro de leña se hace de las ramas de árboles como el gaque, si se causaran daños ya que este tiene un proceso mucho mas lento de recuperación ${ }^{14}$.

\section{Actividades económicas}

Según el censo realizado por CORPONOR en el año 2004, se encontraron actividades agrícolas y pecuarias, dada la información, solo se puede determinar la cantidad de suelo utilizado para siembra, ya que la actividad pecuaria esta dada por cantidad de animales y no por hectárea utilizada.

\footnotetext{
11 Unidad Municipal de Asistencia Técnica Agropecuaria, (UMATA), Pamplona 2001. PBOT

12 PBOT. Pamplona, Censo Rural, 2001

13 Ibíd.

14 Información suministrada por Adolfo Ochoa, funcionario de CORPONOR, en la reunión del CEAM, del mes de Noviembre.
} 
Tabla 2. Usos del suelo por hectáreas y cantidad de animales.

\begin{tabular}{|c|c|c|}
\hline \multicolumn{3}{|c|}{ Usos actuales del suelo } \\
\hline Actividad & Sector pecuario & Sector agrícola \\
\hline Distribución & 7057 animales & 91.7 hectáreas \\
\hline
\end{tabular}

Fuente: CORPONOR ${ }^{15}$

\section{Sector agrícola.}

Tabla 3. Principales cultivos por hectárea.

\begin{tabular}{|l|c|}
\hline \multicolumn{2}{|c|}{ Sector Agrícola } \\
\hline \multicolumn{1}{|c|}{ Cultivo } & Hectáreas \\
\hline Papa & $57.3 \mathrm{Ha}$ \\
\hline Arveja & $23.95 \mathrm{Ha}$ \\
\hline Fresa y hortalizas & $10 \mathrm{Ha}$ \\
\hline
\end{tabular}

Fuente: CORPONOR

Figura 2 Límite entre las Microcuencas de Monteadentro y el Volcán

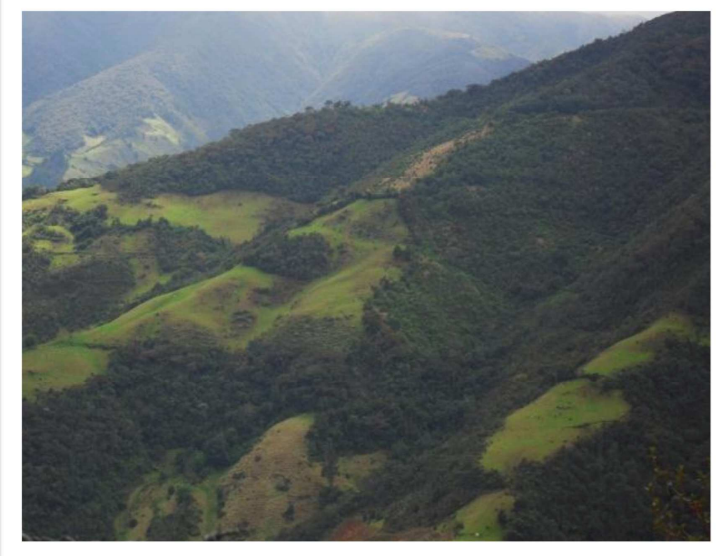

Fuente: Propia
En el sector además se encuentran también pequeños cultivos de maíz, flores, pasto de corte, apio ${ }^{16}$ y siembra de pino, esta ultima, es una especie exótica que consume gran cantidad de agua y provoca resequedad en el suelo e inhibe el crecimiento de otras plantas capaces de retener agua. Además los suelos pasan de ser retentores de agua a repelentes de agua (Estupiñán).

${ }^{15}$ NAVAS Yesid; ALVARES Melva; OCHOA Adolfo; PULIDO Rubiel. Reglamentación del uso del agua en las microcuencas del Volcán y Monteadentro Municipio de Pamplona Departamento de Norte de

Santander. Corporación Autonoma Regional de la Frontera Nororiental “CORPONOR”. Pamplona 2004. 16 CORPONOR. 2004 
Los cultivos en la microcuenca debilitan el manto protector del suelo, sin embargo por encima de los 2800 m.s.n.m. tienen una mayor influencia negativa para las nacientes, puesto que los ecosistemas de páramo son mas frágiles. La destrucción de la vegetación nativa disminuye su capacidad de sostenibilidad y representa una disminución en el caudal para la captación en la parte baja de la microcuenca y además aminora su capacidad de almacenamiento de carbono. En la Figura 2 y 3 se puede evidenciar fácilmente el área que se encuentra protegida y el área que se debe adquirir. Las dos son estratégicas.

\section{Figura 3. Propiedad privada - áreas bajo el} Plan de Administración y manejo ambiental.

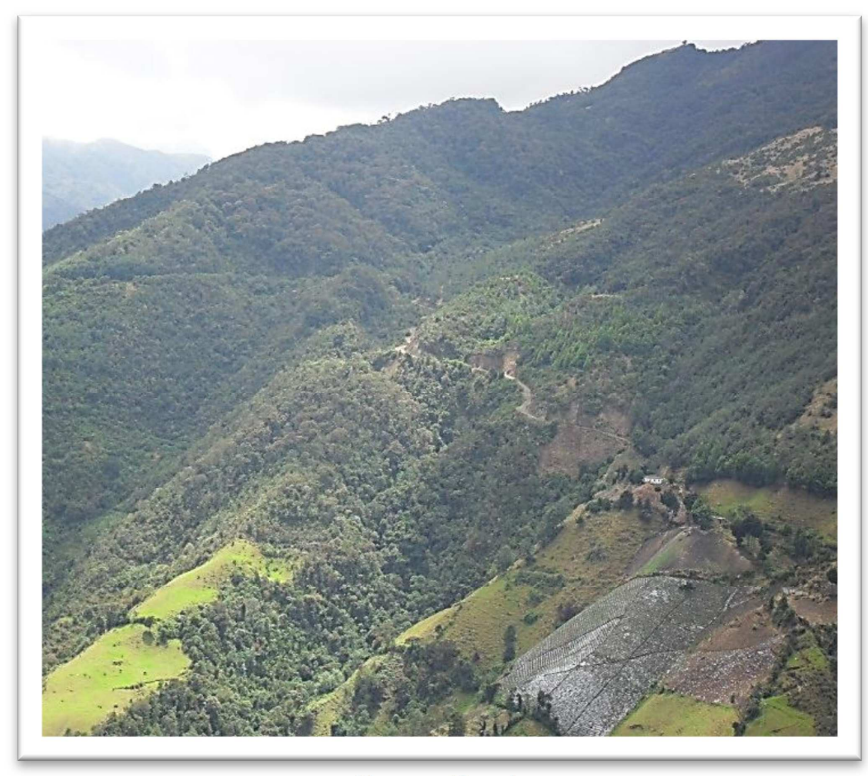

Fuente: Propia

La cobertura vegetal es primordial para la producción del recurso hídrico, porque cumple el papel de interceptar y retener en las ramas y troncos de los árboles el agua que después es eliminada por medio de la evotraspiración y condensación, el agua restante que cae llega hasta el suelo y se infiltra, se almacena en las raíces de esta vegetación o escurre superficialmente. Una vez se extiende la frontera agrícola hacia el páramo y el subpáramo se cambia la cobertura vegetal nativa protectora por el uso del suelo que es asignado para siembra y ganadería, la producción de agua disminuye por la falta de cobertura vegetal dada la función de los suelos del bosque que tanto en sus 
raíces como en el mantillo absorben el agua en periodos lluviosos para mantener el balance hídrico en el tiempo seco y que en ausencia de la cobertura vegetal provoca desequilibrios como el aumento de escorrentía por la disminución en la capacidad de infiltración de los suelos que evita que por el proceso de evaporación el agua vuelva a caer en el mismo lugar.

En las épocas en las que hay ausencia de lluvias, los cultivos requieren de más riego, lo que conlleva a captar mayor cantidad de agua de las quebradas y disminuye la cantidad disponible para las fincas de la parte baja de la microcuenca como para la captación del acueducto del municipio, para regular el consumo en la parte alta de la microcuenca de Monteadentro y mantener agua en las diferentes épocas del año, se realizo la reglamentación ${ }^{17}$ del uso del agua en las microcuencas el Volcán y Monteadentro a partir de sus nacimientos ${ }^{18}$ en su paso por las veredas el Totumo, Alto Grande, El Rosal, Navarro, Jurado, Barrio el Zulia y Monteadentro del municipio de Pamplona hasta su confluencia con la cuenca del Río Pamplonita. En esta reglamentación se especifican $0.15 \mathrm{~L} / \mathrm{Seg}$. caudal máximo de captación por usuario, sin embargo estas fincas a veces utilizan mangueras de mayor capacidad y hacen mal uso del agua dejando estas mangueras en mal estado de tal forma que se fugue el agua o dejando riegos innecesarios, estos usos arriba de la captación en las áreas cercanas a las nacientes disminuyen el caudal de las quebradas que al unirse forman el Río Pamplonita y así generan una disminución en el caudal de $6 \mathrm{~L} / \mathrm{seg}$. en quebradas cuyo caudal es de $20 \mathrm{~L} / \mathrm{seg}^{19}$. La compra de algunas de las fincas de la zona podría mitigar los daños mencionados anteriormente, sin embargo, la imposibilidad de comprar toda la zona amerita tomar otras medidas como la de otorgar incentivos financieros a los propietarios de las fincas para la protección y cuidado del suelo y del uso del agua y además de mecanismos de participación voluntaria y de la revisión constante del ente encargado, en este caso CORPONOR. Para mejorar esta situación se hace necesario seguir la reglamentación de los caudales de las microcuencas de Monteadentro y El Volcán, y proteger las zonas de los bosques nativos de estas áreas estratégicas, mejorar las prácticas de cultivo y hacer usos eficientes del agua entre otras.

En la parte alta de la microcuenca, debido a las bajas temperaturas se cultiva principalmente papa sin alternar con otra variedad de cultivo, como consecuencia de esto, se presentan mayores plagas y pérdida de productividad y fertilidad de los suelos llevando a los cultivadores a utilizar más agroquímicos para el rendimiento de sus

\footnotetext{
${ }_{17}$ Reglamentación dada en Resolución Nº 00190 del 27 de Marzo del 2003.

18 Las nacientes de la microcuencas son 17 (El Borracheral, El Rosal o Monteadentro, El Rascador, Naciente, El Porvenir, El Pedregal, Buena Vista, El Curubito, La Meseta, Tampacal, la Montaña, Las Tomas, El Morrito, Potreritos, La Aguadita, El Encanto)

${ }^{19}$ Información suministrada por el señor Gerardo, Guardabosques de las áreas estratégicas adquiridas por CORPONOR y el municipio.
} 
siembras $^{20}$. En la tabla 4, se mostrara el proceso de producción de la papa y la descripción de los daños que causa al ambiente.

Tabla 4. Etapas de la producción de papa y los daños causados al ambiente.

\begin{tabular}{|c|c|}
\hline \multicolumn{2}{|c|}{ Producción de papa } \\
\hline Etapa & Descripción de daños al suelo y ambiente. \\
\hline Arada & $\begin{array}{l}\text { 1. (Erosión) Alta pérdida de suelo. } \\
\text { 2. Una mediana alteración del suelo. } \\
\text { 3. Se llevan sedimentos a las } \\
\text { quebradas. }\end{array}$ \\
\hline Cosecha & $\begin{array}{l}\text { 1. (erosión) Remoción del suelo, es } \\
\text { baja pero grave cuando no se hace } \\
\text { nada por la conservación. }\end{array}$ \\
\hline Fertilización & 1. el suelo se saliniza \\
\hline Aplicación de pesticidas & $\begin{array}{l}\text { 1. Acumulación media de residuos en } \\
\text { el suelo. } \\
\text { 2. Afectación a la vida microbiana, } \\
\text { que disminuye la fertilidad de los } \\
\text { suelos y la diversidad microbiana. } \\
\text { 3. Cuando el uso es alto se requiere de } \\
\text { mayor cantidad de agua. }\end{array}$ \\
\hline $\begin{array}{l}\text { Almacenamiento y mala disposición de } \\
\text { empaques de pesticidas en el campo. }\end{array}$ & $\begin{array}{l}\text { 1. Contaminación en los suelos. } \\
\text { 2. llegan a contaminar por escorrentía } \\
\text { suelos y aguas. } \\
\text { 3. Cuando queman } \\
\text { inadecuadamente contaminan el } \\
\text { ambiente. }\end{array}$ \\
\hline $\begin{array}{l}\text { Preparación del terreno a través de la } \\
\text { quema. }\end{array}$ & $\begin{array}{l}\text { 1. Alteración de las actividades de los } \\
\text { microorganismos del suelo, } \\
\text { produce cambios químicos. } \\
\text { 2. Algunos reptiles no pueden } \\
\text { sobrevivir al sistema. }\end{array}$ \\
\hline Lavada de la papa en la finca. & $\begin{array}{l}\text { 1. Lleva sedimentos a través de las } \\
\text { quebradas. }\end{array}$ \\
\hline
\end{tabular}

${ }^{20}$ Información suministrada por Rubier Pulido, funcionario de CORPONOR. 


\begin{tabular}{|c|c|}
\hline Tumba de rastrojos altos. & $\begin{array}{l}\text { 1. Disminución en los caudales de } \\
\text { agua. } \\
\text { 2. Homogenización del paisaje } \\
\text { 3. perdida de habitad para aves y } \\
\text { alimento para distintos animales. }\end{array}$ \\
\hline $\begin{array}{l}\text { Siembra hasta los retiros de las } \\
\text { quebradas }\end{array}$ & $\begin{array}{l}\text { 1. Se pierde la regularización del } \\
\text { balance hídrico. }\end{array}$ \\
\hline Aplicación de abonos or & $\begin{array}{l}\text { 1. Posible incorporación de plantas de } \\
\text { otros sistemas. }\end{array}$ \\
\hline
\end{tabular}

Fuente: AGUILAR (2008)

Cuando se seleccionan lotes en pendiente y susceptibles a erosión, se causan daños a los recursos naturales y si para la preparación de estos cultivos además se hace uso de la quema, lleva a la destrucción del mato vegetal y a la disminución en la producción de agua. Además, la producción de papa en ecosistemas frágiles como los ecosistemas de páramo afectan la biodiversidad. De otro lado la escogencia de la semilla hecha por los pequeños productores generalmente trae consecuencias como elevadas plagas, estos campesinos eligen semillas inadecuadas para disminuir sus costos y deben utilizar altas dosis de plaguicidas que por escorrentía terminan en los causes de las quebradas y afectan nocivamente la fauna. Teniendo en cuenta las externalidades negativas de la producción de papa, es pertinente mejorar las técnicas de cultivo en la parte baja de la microcuenca y detener la expansión de la frontera agrícola en la parte alta, además en aquellas zonas estratégicas es necesaria la recuperación y propiciar procesos de organización y capacitación a los campesinos para lograr un desarrollo sostenible en compañía de las autoridades competentes. FEDEPAPA (2003)

\section{Sector pecuario}

Las actividades de producción pecuaria como el pastoreo, requieren de la conversión de terrenos con bosques nativos en potreros, la práctica lleva a un gran deterioro del suelo, pero los propietarios de terrenos en los páramos deben utilizarlos para esta actividad o destinarlos a la siembra de papa para que estos les sean productivos. 
Tabla 5. Numero de animales en la microcuenca de Monteadentro

\begin{tabular}{|c|c|}
\hline \multicolumn{2}{|c|}{ Sector pecuario } \\
\hline Animales & Cantidad \\
\hline Bovinos & 452 \\
\hline caballos & 108 \\
\hline Aves & 2.480 \\
\hline truchas & 4.000 \\
\hline Porcinos & 10 \\
\hline Conejos & 3 \\
\hline Caprinos & 4 \\
\hline TOTAL & 7.057 \\
\hline
\end{tabular}

Fuente: CORPONOR

Debido al cambio de la vegetación boscosa y al tránsito de animales pesados como los bovinos y los caballos, el suelo se compacta provocando mayor escorrentía, lo que quiere decir, implicaciones sobre el almacenamiento del agua en la microcuenca. La ganadería endurece el suelo y le quita sus propiedades de permeabilidad, por lo que el ciclo normal de agua es alterado. Esta compactación no solo trae efectos negativos para el ciclo del agua sino para la retención de oxigeno y el crecimiento del mismo pasto para el ganado en un periodo prolongado. (AVELLANEDA).

\section{Instrumentos de política ambiental utilizados en la actualidad para la protección de las nacientes:}

Los instrumentos utilizados para la protección del medio ambiente son los mecanismos voluntarios, regulaciones, gasto gubernamental e incentivos financieros, según Jacobs (1995)la decisión para utilizar estos mecanismos puede ser evaluada por los criterios de efectividad, motivación, costos administrativos, eficiencia y equidad. La eficacia es el primer criterio que se debe tomar en cuenta para elegir entre los diferentes instrumentos. Para el caso de la protección de nacientes con el fin de suministrar agua a la población de Pamplona, teniendo en cuenta que se trata de un bien publico, es una acción que le compete directamente al gobierno ya que los demás instrumentos pueden ser ineficientes, aunque esto no implique que sean los actores sociales quienes decidan sobre los bienes que desean y además sean participes de las decisiones relacionadas a la provisión y cuidado del mismo.

Los instrumentos de política económica permiten el mejoramiento y la protección ambiental, los impuestos proporcionan los recursos para destinar al gasto, que a su vez proporciona recursos a los individuos a través de los entes gubernamentales que se 
encargan de administrarlos y además a través de regulaciones pueden lograr un limite en la cantidad de contaminación permitida. Aunque la población decida invertir mas en la protección del medio ambiente para ellos mismos, para las generaciones futuras y que el cuidado del medio ambiente sea una prioridad nacional clave “... Una economía de mercado no puede resolver automáticamente estos problemas...”. El objetivo propuesto solo se puede alcanzar "...Si y solo si el Estado modifica sus impuestos, su gasto o sus reglamentaciones. El trueno de la historia mundial se oye en la política fiscal porque los impuestos y el gasto son poderosos instrumentos de cambio social." (Samuelson, Nordhaus. 2002. Pág. 281).

El gasto de gobierno puede ser efectuado mediante subsidios o por inversión directa del Estado, en el primer caso estos podrían estimular a los propietarios a mejorar el uso de la tierra y a conservar y proteger las áreas ecológicas de mayor sensibilidad a las actividades humanas. En el segundo caso se garantizaría la protección de las áreas estratégicas, esta sería la medida efectiva para el cumplimiento de la meta ambiental (la producción y calidad de agua). En ausencia de recursos para la compra de los predios ${ }^{21}$ en donde se encuentran ubicados los nacimientos de esta microcuenca, El Municipio de Pamplona, EMPOPAMPLONA y CORPONOR 22 han realizado el pago a los dueños de estas fincas por cercar algunos de los principales nacimientos que aportan agua a las quebradas de Monteadentro y García desde el año 2006 y 2007, por medio del convenio de protección de nacientes, con el fin de evitar la llegada de animales como las vacas y los caballos hasta allí.

Además CORPONOR en compañía del Comité de Educación y Gestión Ambiental de Pamplona, han hecho uso de los mecanismos voluntarios y llevan a cabo campañas de educación para evitar la siembra de forma vertical en los linderos para disminuir los deslizamientos hacia los caudales y la perdida de la capa superior del suelo, de esta manera, también se disminuye la cantidad de agua para riego, pues esta no drena rápidamente como cuando se siembra de manera vertical.

Beneficios ambientales del uso del suelo productor y protector de agua en la microcuenca de Monteadentro.

Los ecosistemas ubicados en la parte alta de la microcuenca de Monteadentro, producen y proveen servicios ambientales de vital importancia para los pamploneses. Estos servicios potenciales por la compra de las fincas ubicadas en la parte alta de Monteadentro pueden ser de uso directo como la extracción de madera de manera

21480 hectáreas con un valor aproximado de 590.000 .000 de pesos

22 Mediante la ley 99 de 1993 se creo el Ministerio del Medio Ambiente y los Recursos Naturales y se creo el SINA que en el articulo 23 señala la Naturaleza jurídica de las corporaciones autónomas regionales para "administrar dentro del área de su jurisdicción, el medio ambiente y los recursos naturales renovables y propender por su desarrollo sostenible" 
sostenible, recreación, alimentos, biodiversidad y belleza escénica o de uso indirecto (biodiversidad, microclimas, protección de la cuenca, secuestro de carbono y demás funciones ecológicas). El valor de los servicios ambientales depende de los beneficios que representa para los pobladores

Figura 4. Área reforestada de la Microcuenca el Volcán, límite con la Microcuenca de Monteadentro. Fuente: Propia

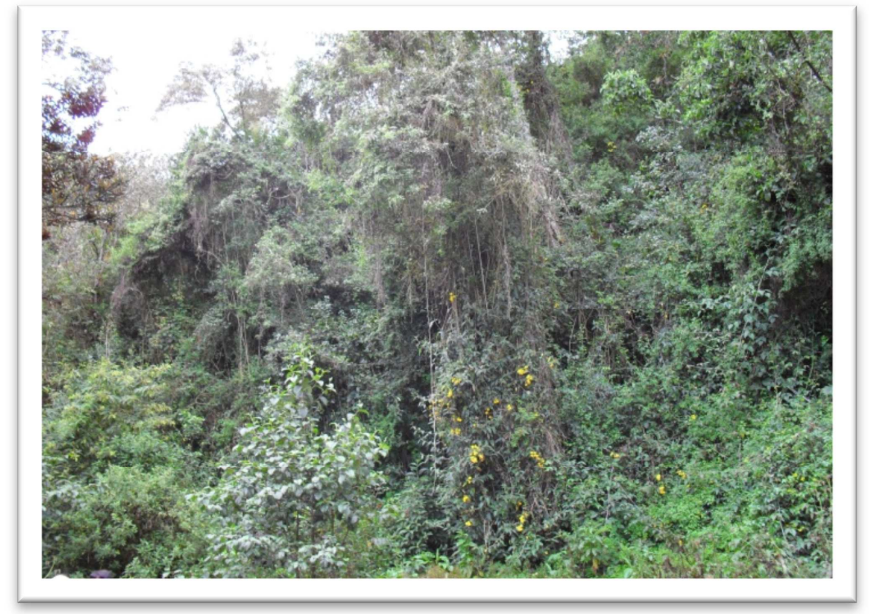

reconocida es de gran calidad visual y con alta $p$ turismo.

\section{Oferta hídrica}

La vegetación de estos páramos se caracteriza por la gran capacidad de almacenar y retener agua, estos ecosistemas tienen gran potencial para interceptar y así regular las aguas superficiales y subterráneas, es decir mantener el balance hídrico. El agua es uno de los servicios ambientales más importantes en la zona de la microcuenca de Monteadentro.

Según los datos suministrados por el PBOT de Pamplona (2001), la precipitación promedio es esta microcuenca es de $912.50 \mathrm{MM} / \mathrm{AN} O$ en un área de $10.83 \mathrm{Km} 2$, para una oferta global de 6.670,603 M3/AÑO, donde al dejar 2.668,241 de caudal ecológico resulta una oferta total de 4.002,361 M3/AÑO.

\footnotetext{
${ }^{23}$ HERRADOR Doribel; DIMAS Leopoldo. Valoración económica del agua para el área metropolitana de San Salvador.
} 


\section{Hábitat de especies}

Según el estudio realizado para el Plan de Administración y Manejo Ambiental, se encontró en el diagnostico que en la zona habitan 98 especies vegetales y 295 especies animales.

\section{Fauna}

Las especies registradas en el Plan de Acción Regional en Biodiversidad para el departamento que elaboro el Instituto de Investigación de Recursos Biológicos Alexander Von Humboldt y CORPONOR son los mamíferos (Agouti taczanowskii, Nasuella olivacea, Sciurus granatensis y Sylvilagus brasiliensis).

Además de estos animales, se han encontrado por observación los siguientes mamíferos y aves: faras, ratas de monte, ardillas, armadillos, lochos (venados), guaches, cabritos, comadrejas, puerco espines, pavas, torcazas, ciotes, copetones, bijarcos, pechirojos, miracielos, azulejos, colibríes, zorros, guaras, golondrinas y mapuros ${ }^{24}$.

Según el profesor Pedro Rodríguez, en la microcuenca el Volcán habitan 42 especies de aves, por tanto, se puede deducir que estas mismas especies podrían estar en la microcuenca de Monteadentro. Algunas de estas aves son de alta frecuencia mientras que otras lo hacen de forma moderada, poca u ocasional, pero la visita de estas aves esta relacionada con los árboles o insectos de la microcuenca.

\section{Vegetación}

La vegetación de la parte alta de la microcuenca se puede encontrar dividida en 3 sucesiones de especies, donde en la primera se encuentra el pajonal precursor, el frailejón plateado y el frailejón amarillo, en la segunda se hallan el chite, romero hojilargo y uva camarona, en la última se encuentran el romero blanco, cucharo, encenillo, frailero, uvas de monte y gaque.

Entre las especies que se pueden albergar en la zona por un plan de reforestación se encuentran: el mortiño (Hesperomeles goudotiana), arrayan, hayuelo, copey o tampaco, chuque o garrocho, pino romerón, mano de oso (Oreopanax bogotensis Cuatrec), uva camarona (Macleania rupestris) y cerezo, el sangragado, caucho, acacias, sauces, robles, el nogal, nectarinas, gramíneas, urapan, holly, abutillon y el mangle. Estas especies son importantes debido a la función de alimento que cumplen para las aves principalmente y como protectores y productores de agua.

Secuestro de carbono.

${ }^{24}$ Plan de Administración y Manejo Ambiental, Área Protegida el Volcán, Municipio de Pamplona. 
Los suelos de los páramos no solo son almacenes de agua, estos también almacenan gran cantidad de materia orgánica, de la cual, la mitad corresponde a carbono y puede ser conservada prolongadamente por las bajas temperaturas. El carbono es mejor conservado en lo profundo del suelo, por esta razón es necesario no descubrir los suelos para evitar la fuga de carbono. (HOFSTEDE Y MENA) El secuestro de carbono es un servicio ambiental de los más relevantes que prestan principalmente los árboles y que consiste en absorber y almacenar el carbono atmosférico como biomasa. Cuando no existen usos apropiados del suelo y daños a los ecosistemas, puede existir emisión de gases de efecto invernadero.

El secuestro de carbono es una externalidad positiva, que no sólo tiene impactos locales sino globales, el hecho de que en cualquier lugar del mundo exista el servicio ambiental de almacenamiento de carbono en los bosques, puede mitigar los nocivos efectos de los gases de efecto invernadero, por esta razón tiene un mercado global que es impulsado por el protocolo de $\mathrm{Kyoto}^{25}$, en el cual los países desarrollados pueden comprar bonos verdes a países en desarrollo, y de esta manera cumplir con los límites establecidos internacionalmente ${ }^{26}$.

La venta de absorción de carbono en el mercado mundial, no solo ayuda a mitigar los efectos nocivos de los gases de efecto invernadero, sino que es una alternativa para proteger los bosques de América Latina. Este mercado tiene sus orígenes en 1990, y es una idea de la empresa Applied Energy Services, para compensar la contaminación que ella causaba, se inicio en los bosques nativos de Guatemala a un precio de 0.19 dólares la tonelada. Ya en 1997, el gobierno de Costa Rica realiza los certificados y cuesta 10 dólares la tonelada y en la actualidad el precio se encuentra en 25 dólares la tonelada aproximadamente. (MARTINO, VAN HOFF (21:4-9)

\section{MÉTODO}

\section{Muestra}

La población tomada para realizar el estudio fueron los usuarios de acueducto y alcantarillado del municipio de Pamplona Norte de Santander puesto que estos son los beneficiarios por la producción y calidad de agua. Esta población es heterogénea a nivel socioeconómico y esta conformada por 11723 usuarios $^{27}$ divididos en cuatro estratos además en usuarios comerciales, industriales, especiales y oficiales. Debido a que la población es grande y diversa se llevo a cabo un muestreo aleatorio estratificado con

\footnotetext{
${ }^{25}$ Es un acuerdo internacional de lucha contra el cambio climático, firmado en 1997, apoyado por cien gobiernos de todo el mundo. SOLUCIONES PARA UN MUNDO MEJOR. (2009)

${ }^{26}$ Fundación Para El Desarrollo Sustentable. Construyendo un mejor mundo.(2003)

${ }^{27}$ Estrato 1 - 1844, estrato 2 - 3607, estrato 3 - 4010, estrato 4 - 1489, comercial 649, industrial 11, especial 34 y oficial 79
} 
afijación proporcional y se procedió a unir los estratos comercial e industrial y especial y oficial.

\section{Método de valoración contingente}

Los beneficios que reporta un bien pueden ser medidos por lo que las personas están dispuestas a pagar por ellos. Sin embargo medir la disposición de pago por la calidad del medio ambiente no es así de sencillo, pues la inexistencia de un mercado imposibilita hacerlo directamente. (FIELD, B. FIELD, M 2003). La medición cuantitativa del valor económico de los recursos naturales es un reto para los economistas. La valoración presenta problemas por la dificultad que se encuentra en la revelación de preferencias, dado que revelar sinceramente los deseos de provisión de bienes ambientales como de bienes públicos puede representar costos adicionales para los usuarios por medio de impuestos y tasas existen métodos para medir el valor económico de los recursos y servicios ambientales ${ }^{28}$.

Por precios y mercado se pueden encontrar tres tipos de métodos. Los métodos directos de mercado, indirectos de mercado y directos de no mercado. Los métodos de costo de oportunidad y costos de recuperación y de restauración hacen parte de los métodos directos de mercado y el de coste de desplazamiento, junto con el de precios hedónicos, son clasificados como métodos indirectos de mercado. En tercer lugar se pueden encontrar los métodos de preferencias declaradas, el cual se hace por medio de un cuestionario a la población de forma aleatoria y esta clasificado entre los métodos directos de no mercado, como lo es el caso del Método de Valoración Contingente. ${ }^{29}$

El método utilizado fue de valoración contingente (MVC), este método fue desarrollado por Cummings, Brookshire y Schulze en 1986 y a profundidad y popularizado por Mitchell y Carson en 1989. El método busca que la persona revele directamente sus preferencias por un bien ambiental expresando su disposición a pagar y consiste en realizar una serie de preguntas directas a través de la presentación de una situación hipotética de la mejora de una condición, en este caso la mejora en la producción y calidad de agua. Uno de los supuestos teóricos del método es la racionalidad del consumidor, puesto que le da la capacidad para conseguir la máxima utilidad por medio del consumo de ciertos bienes teniendo en cuenta su presupuesto y conociendo la información de quienes intervienen en el mercado (Rojas, Pérez y Peña 2001).

Como menciona AZQUETA (1999) las cosas tienen un valor en la medida en que las personas se lo dan, el valor del medio ambiente, cumple con unas funciones que afectan

28 STIGLITZ Joseph, Economía del sector Publico. 2 edición. Antoni Bosch Editor.

29 AZQUETA Diego (1999) Valoración Monetaria de la Calidad Ambiental, Cáp. 5, McG Hill

Interamericana de España. 
positivamente al bienestar de las personas, por tanto, cada persona es el mejor juez sobre su propio bienestar (principio de la soberanía del consumidor). El método de valoración contingente permite conocer el valor que le da el conjunto de la sociedad a la microcuenca, se toma en cuenta la democracia de mercado puesto que cada persona expresa cuanto esta dispuesto a pagar.

Las razones de utilización del método de Valoración Contingente para valorar el conjunto de servicios ambientales de la Microcuenca de Montedentro son: la revelación directa de las preferencias de los consumidores por el bien de uso (calidad y producción de agua), pero además que el ciudadano puede expresar su disposición a pagar por aquellos valores de no uso (opción y cuasi opción) como la conservación del habitad de especies y belleza paisajística entre otros.

\section{Limitaciones del método}

Entre las limitaciones que presenta el método se encuentran los sesgos en la respuesta, estos sesgos pueden ser operativos o instrumentales. Existen cinco sesgos instrumentales que pueden condicionar las respuestas finales. Estos son: el originado por el punto de partida ${ }^{30}$, sesgo del vehículo ${ }^{31}$, de información o sesgo de dosis respuesta, en cuarto lugar se encuentra el sesgo del entrevistador y por ultimo el sesgo del orden. (AZQUETA, 1999)

De los sesgos no instrumentales, se pueden mencionar dos: uno de los que presenta mayores problemas puesto que las respuestas pueden variar sobre valoración del bien al ser entendida la propuesta como muy hipotética, este sesgo es llamado sesgo hipotético ${ }^{32}$ y en segundo lugar se encuentra el sesgo estratégico, que corresponde a la respuesta poco honesta para salir favorecido en la decisión final.

La crítica a los métodos de preferencias declaradas se deriva de la distancia que hay entre el excedente compensado y el excedente equivalente, pues para bienes de mercado estos dos no difieren.

La diferencia se da por tres razones.

1. Asignación que no corresponde a los derechos de propiedad para la construcción del mercado y la formulación de la pregunta.

\footnotetext{
${ }^{30}$ Para evitar este sesgo se llevo a cabo una encuesta piloto, con una respuesta abierta, de esta manera se procedió mas adelante a elaborar los rangos.

${ }^{31}$ Este elemento se elaboro de manera que fuera incluyente, todos tendrían que pagar su recibo de agua, pero no todos deberían pagar impuestos, así que el vehículo elegido fue el recibo de agua.

${ }^{32} \mathrm{Al}$ encuestar se presento este sesgo en una cantidad muy pequeña, se percibieron 4 encuestas con este sesgo.
} 
2. Factores psicológicos, los individuos asumen diferente las perdidas y las ganancias como lo sugirió Kahneman y Tversky (1979)

3. Según Hanemann (1991). Por existir muchos sustitutivos de los bienes públicos, el excedente compensado por un cambio positivo tiende al excedente equivalente, pero si ocurre lo contrario la distancia entre los dos aparece.

\section{Encuesta}

La herramienta utilizada para el propósito fue la encuesta, esta se realizó en el sitio y constaba de tres partes, en la primera parte se les informaba a los encuestados sobre el origen del recurso hídrico que se toma para suplir la demanda de agua de los pamploneses, las condiciones actuales de la microcuenca y los daños causados por los humanos y animales que habitan las áreas estratégicas como el caso hipotético de los beneficios de la compra, reforestación y conservación de la misma. La segunda parte de la encuesta preguntaba por la disposición a pagar por la compra de los terrenos donde se encuentran ubicados algunos de los nacimientos de la siguiente manera: “¿Estaría Ud. dispuesto a pagar una suma mensual durante un año, con el fin de que se compren las áreas estratégicas de la Microcuenca de Monteadentro, se reforesten y se protejan los bosques y ecosistemas de estas áreas, y de esta manera asegurar el suministro de agua proveniente de la microcuenca de Monteadentro para su familia?", sí la respuesta era afirmativa se le sugerían 6 rangos, donde el encuestado debería elegir. El menor rango se definió como $<999 \$$ y el ultimo como $>15.000 \$$. Para la elección de estos rangos se elaboro una encuesta piloto aplicada a 20 personas de los diferentes estratos, donde la opción de respuesta a la disposición a pagar era abierta. Además se incluyó una pregunta dirigida a conocer la disposición a pagar por los demás servicios ambientales que brinda la microcuenca con el fin de conocer aquellos valores de no uso. La tercera parte incluía datos socioeconómicos, que corresponden al jefe de hogar o en su defecto al responsable de pagar los servicios públicos del establecimiento.

\section{Resultados}

Al realizar la pregunta por la disposición a pagar (DAP) por la compra, reforestación y protección de las áreas estratégicas de la Microcuenca de Monteadentro, el $77.89 \%$ respondieron de forma afirmativa y el $22.10 \%$ de forma negativa. Mientras que a la pregunta por la DAP por los servicios ambientales diferentes a la producción y calidad de agua solo el $46.31 \%$ manifestaron disposición a pagar 
Tabla 6. Respuestas afirmativas por estrato

\begin{tabular}{|l|c|c|c|c|}
\hline \multicolumn{1}{|c|}{ Usuario } & $\begin{array}{c}\text { (producción } \\
\text { y calidad) }\end{array}$ & $\begin{array}{c}\text { Porcentaje } \\
\text { por estrato }\end{array}$ & $\begin{array}{c}\text { Rango de mayor } \\
\text { respuesta }\end{array}$ & $\begin{array}{c}\text { Servicios } \\
\text { ambientales* }\end{array}$ \\
\hline Estrato 1 & 13 & $86.66 \%$ & $>999$ & 8 \\
Estrato 2 & 20 & $68.96 \%$ & $2000-4999$ & 17 \\
Estrato 3 & 24 & $72.72 \%$ & $2000-4999$ & 17 \\
Estrato 4 & 11 & $91.66 \%$ & $5.000-9.999$ & 6 \\
Comercial e & 5 & $100 \%$ & $5000-9.999$ y 10.000- & 4 \\
Industrial & 1 & $100 \%$ & $14.999 * *$ & 0 \\
Especial & $y$ & & $2000-4.999$ & \\
Oficial. & & & & 52
\end{tabular}

Fuente: cálculos propios a partir de las encuestas.

* Más abajo se dará la información detallada de la DAP por servicios ambientales.

** El numero de encuestas es muy bajo, 2 respuestas se ubicaron en un rango y 2 mas en el otro.

Figura 5. A partir de los datos de la encuesta.

\section{Ubicacion De La Poblacion Total Por Rangos En Pesos}

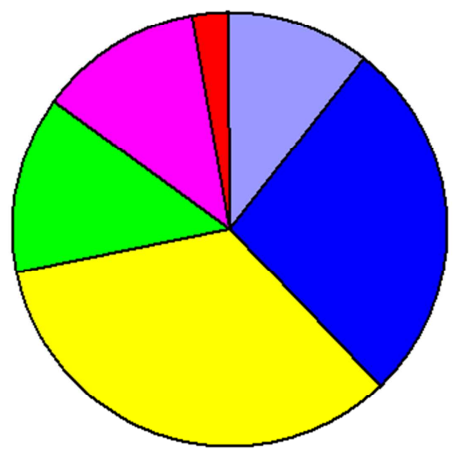

1000-1999

$2000-4999$

5000-9999

$10000-15000$

$<15000$

En comparación con otros estudios revisados donde han utilizado el método de valoración contingente, las respuestas de rechazo o en desacuerdo encontradas en este estudio son menores, pues los demás muestran porcentajes del $30 \%$ y hasta $40 \%$. En el presente estudio, el $22.10 \%$ que respondieron de forma negativa manifestaron los siguientes motivos para no hacerlo: 
Tabla 7. Motivos sobre la no disposición a pagar.

\begin{tabular}{|l|c|c|}
\hline Concepto & Respuestas & Porcentaje \\
\hline Gestión del Estado & 11 & $52.98 \%$ \\
Limitación de recursos (Restricción & 7 & $33.33 \%$ \\
presupuestal) & 3 & $14.28 \%$ \\
El monto se debe sacar de otros recursos & & $\mathbf{1 0 0}$ \\
\hline TOTAL & $\mathbf{2 1}$ & \\
\hline
\end{tabular}

Fuente: Cálculos propios

*A pesar de no existir dentro del cuestionario una pregunta de la razón para no presentar una disposición de pago. Una vez terminada la encuesta, se le preguntaba a la persona su razón.

Estas respuestas indican que los pamploneses están de acuerdo con el proyecto y son consientes de la necesidad, sin embargo, el $22.10 \%$ que respondieron de forma negativa expresan que la corrupción y el destino de los recursos a porcentajes en "contratación", los hace abstenerse a contribuir. Por otro lado, existe desconocimiento de la procedencia de los recursos que administra el estado por lo que un $14.28 \%$ de la población que no esta dispuesta a pagar, sugiere que "el Estado lo compre"

Teniendo en cuenta las variables sociodemográficas (edad, genero, habitantes por vivienda y estado civil), se puede decir que, en promedio, los hogares están conformados por cuatro personas y que de los encuestados de estado civil soltero, un $80.85 \%$ respondieron estar dispuestos a pagar y del grupo de los casados el porcentaje que presento disposición a pagar es del $75 \%$, de otro lado, teniendo en cuenta la variable genero, de los hombres encuestados, el $77.27 \%$ tienen disposición a pagar y de las mujeres el $78.43 \%$. A partir de estos resultados y de lo arrojado por el modelo, el género y estado civil de la población no inciden en la DAP.

Tabla 8. Respuestas afirmativas por edad.

\begin{tabular}{|l|c|c|c|}
\hline Edad & Numero de respuestas & Porcentaje por edad & Porcentaje total. \\
\hline Menor de 20 & 6 & $100 \%$ & $8.10 \%$ \\
$20-30$ & 14 & $77.77 \%$ & $18.91 \%$ \\
$30-50$ & 30 & $73.17 \%$ & $40.54 \%$ \\
$50-60$ & 22 & $84.61 \%$ & $29.72 \%$ \\
Mas de 60 & 2 & $50 \%$ & $2.70 \%$ \\
\hline \multicolumn{3}{|r}{} \\
\hline
\end{tabular}

Fuente: Cálculos propios 
Los resultados arrojados permiten hacer algunas hipótesis sobre la mayor DAP entre los menores de 20 años y aquellos que están entre los cincuenta y 60 años. En el caso del primer grupo las nuevas cátedras de educación ambiental pueden incidir en el reconocimiento y apropiación del problema, mientras que en el segundo grupo podría existir una preocupación por las generaciones futuras.

A partir de los datos socioeconómicos, se pueden formular las siguientes hipótesis, dentro de la población, la de mayor DAP la explica el nivel educativo, con la excepción del nivel pregrado, que podría llevarnos a otra hipótesis y es que se encuentran ante un costo de oportunidad donde la preferencia por estudiar anula la posibilidad de ingresos por vía del trabajo o se encuentren desempleados.

Tabla 9. Respuestas afirmativas por nivel de educación

\begin{tabular}{|l|c|c|}
\hline \multicolumn{1}{|c|}{ Nivel de educación } & $\begin{array}{c}\text { Respuestas } \\
\text { Afirmativas }\end{array}$ & \% dentro del grupo. \\
\hline Ninguna & 0 & 0 \\
Primaria & 12 & $70.38 \%$ \\
Secundaria & 30 & $78.94 \%$ \\
Técnico & 12 & $92.30 \%$ \\
Pregrado & 11 & $73.33 \%$ \\
Postgrado & 9 & $89.81 \%$ \\
\hline
\end{tabular}

Fuente: Cálculos propios

Tabla 10. Respuestas afirmativas por ocupación

\begin{tabular}{|l|c|c|}
\hline \multicolumn{1}{|c|}{ Clasificación } & Respuestas afirmativas & \% dentro del grupo \\
\hline Sin actividad & 12 & $63.15 \%$ \\
Trabajador independiente & 19 & $70.37 \%$ \\
Empleado & 26 & $86.66 \%$ \\
Pensionado & 7 & $100 \%$ \\
Estudiante & 10 & $83.33 \%$ \\
\hline
\end{tabular}

Fuente: Cálculos propios 
Los beneficios por la compra de las áreas estratégicas en la evaluación de los valores de uso, teniendo encuesta los rangos de mayor preferencia en cada estrato serían:

Tabla 11. Beneficios mensuales por

\begin{tabular}{|c|c|c|c|c|}
\hline \multirow[t]{2}{*}{ Usuario } & \multirow{2}{*}{$\begin{array}{l}\text { Población } \\
\text { Total }\end{array}$} & \multirow{2}{*}{$\begin{array}{l}\text { Población } \\
\text { (DAP) }\end{array}$} & \multicolumn{2}{|c|}{ Beneficios Mensuales } \\
\hline & & & Min. & Máx. \\
\hline Estrato 1 & 1844 & 1598 & 1598 & 1.596 .402 \\
\hline Estrato 2 & 3607 & 2487 & 4.971 .513 & 12.432 .513 \\
\hline Estrato 3 & 4010 & 2916 & 5.829 .084 & 14.577 .084 \\
\hline Estrato 4 & 1489 & 1364 & 6.820 .000 & 13.638 .636 \\
\hline Comercial e & 660 & 660 & 3.300 .000 & 9.899 .340 \\
\hline $\begin{array}{c}\text { Industrial } \\
\text { Especial y Oficial }\end{array}$ & 113 & 113 & 225.887 & 564.887 \\
\hline \multicolumn{3}{|l|}{ TOTAL } & 21.148 .082 & 52.708 .862 \\
\hline
\end{tabular}

Fuente: Cálculos propios

En la evaluación para los beneficios de la compra de las áreas en los demás servicios ambientales, siguiendo el mismo procedimiento anterior serian:

\begin{tabular}{|l|c|c|c|}
\hline Usuario & $\begin{array}{c}\text { \% (DAP) por } \\
\text { usuario }\end{array}$ & Media & $\begin{array}{c}\text { Beneficios } \\
\text { mensuales }\end{array}$ \\
\hline Estrato 1 & $53.33 \%$ & 3006.65 & $2.955 .536,95$ \\
Estrato 2 & $58.62 \%$ & 9211.76 & $6.155 .460,64$ \\
Estrato 3 & $51.51 \%$ & 2882.35 & $5.952 .052,75$ \\
Estrato 4 & $50 \%$ & 1666.54 & $1.239 .905,76$ \\
Comerciales & $80 \%$ & 7000 & 3.696 .000 \\
Industriales & $0 \%$ & 0 & 0 \\
Especiales y Oficiales & \multicolumn{3}{|l}{} \\
\hline TOTAL & & \\
\hline
\end{tabular}

El R2 del modelo es muy bajo (0.1298) sin embargo, la revisión de la literatura, sugiere que para variables dicotómicas, suele dar ese tipo de resultados. Las variables que arrojo ser significativas corresponden a los datos que se pudieron inferir del análisis estadístico descriptivo, siendo el ingreso, la educación y la ocupación las que explican la probabilidad de DAP, sin embargo el modelo arrojo significancia para el género mientras que en las estadísticas no se puede ver mayor proporción de diferencia entre las dos. 


\section{CONCLUSIONES}

Teniendo en cuenta el diagnostico anterior y contando con que el agua no tiene sustitutos para muchas de las actividades que se llevan a cabo en la vida diaria, que es un bien esencial para la vida y el medio ambiente, y que se encuentra altamente vulnerable su producción a nivel mundial y local como consecuencia de la destrucción del hábitat que produce este recurso renovable ALDANA (2003). Se hace necesaria la toma de decisiones para garantizar la oferta de agua en la ciudad de Pamplona en la actualidad y para las generaciones futuras.

Existe en la población una disposición de pago significativa por el valor de uso de la microcuenca y un poco menor por la disposición de pago de los valores de no uso, sin embargo, la falta de credibilidad en las instituciones principalmente por motivos de corrupción, inhibe la voluntad de los actores sociales de apropiarse de la problemática ambiental presentada en la microcuenca de Monteadentro con respecto a la producción y calidad de agua.

Tal como se pretendía averiguar, los beneficios sociales y ambientales por la compra de las áreas estratégicas de la microcuenca de Monteadentro para los Pamploneses tomando el valor mayor del rango es de 632.506 .344 pesos anuales, indicando que los beneficios sociales y ambientales son mayores a los costos de llevar a cabo el proyecto. Además sí se tienen en cuenta los beneficios sociales por los demás servicios ambientales, estos revelarían un mayor valor de la Microcuenca para los pamploneses, puesto que los beneficios ascenderían a 872.493 .813 pesos. Así pues, el excedente en el primer caso sería de 42.506 .344 pesos y en el segundo sería de 282.493 .813 pesos.

Las condiciones ambientales y económicas actuales sugieren la necesidad de llevar a cabo cambios en la distribución de los recursos públicos, el estudio reveló el valor que tiene para la población el recurso hídrico como el conocimiento de la importancia del agua para la vida. La valoración se realizó con el fin de justificar el gasto publico en la compra de las áreas estratégicas, más no implica que sea necesario el aumento de la contribución de los habitantes. El valor que tiene para la población la microcuenca le puede sugerir a los entes públicos que se destinen recursos a la adquisición de las áreas estratégicas que hace falta comprar, pero además la revisión de los demás servicios ambientales que presta la microcuenca y la coyuntura mundial, abre nuevas posibilidades locales de financiación al proyecto con la opción de la venta de carbono propuesta en el protocolo de kyoto. La opción de venta de carbono en el mercado mundial no es solo un gran potencial para la financiación sino una alternativa de desarrollo para el resto de la microcuenca, que permitiría una explotación sostenible y con ello un aumento en los beneficios al resto de la población de área urbana 


\section{BIBLIOGRAFÍA}

- Alcaldía Municipal de Pamplona. Mapas [Consultado 8 Nov. 2009] Disponible en: http:/ / www.pamplona-nortedesantander.gov.co/sitio.shtml?apc $=\mathrm{m}-\mathrm{f1}-\mathrm{-} \& \mathrm{~m}=\mathrm{m}$

- $\quad$ ALDANA, Camilo. Las externalidades forestales. En: Conif.[en línea]. (2003) [consultado 25 Sep. 2007] Disponible en: http://www.Conif.org.co/images/Las\%20Externalidades\%20Forestales.doc

- Aguilar Tarcisio. Proyecto Páramo Andino - Colombia. Instituto Humbolt. En línea (2008). [consultado 14 Nov. 2009]. Disponible en:

- http://www.humboldt.org.co/chmcolombia/servicios/jsp/buscador/documentos /Caracterizacion_cultivos_papa_paramo_Belmira.pdf

- AVELLANEDA Alfonso. Alteración del páramo de Chocontales en Boyacá por Ganadería y aplicación de plaguicidas en papa. Impacto ambiental páramo de Choconta. [en línea] [consultado el 14 de Nov del 2009] Disponible en: http://www.lablaa.org/blaavirtual/geografia/congresoparamo/alteracion.pdf

- AZQUETA Diego. Valoración Monetaria de la Calidad Ambiental, McG Hill Interamericana de España, 1999

- ESTUPIÑÁN Bravo, Luis Hernando. Impacto causado en el suelo por las plantaciones de pino en el páramo de Gachaneca. Impacto de plantaciones de pino en el páramo. [En línea] [Consultado el 20 de Nov. De 2009]. Disponible en: http://www.lablaa.org/blaavirtual/geografia/congresoparamo/impacto.pdf

- FEDEPAPA. Ministerio de Ambiente, Vivienda y Desarrollo Territorial. Guía Ambiental para el cultivo de la papa. Bogota [En línea] (2003). [consultado el 13 de Nov. 2009]. Disponible en:

http://www.gobant.gov.co/organismos/agricultura/papa/cadena $\% 20 \mathrm{papa} / g u i a \%$ 20ambiental.pdf

- FIELD, Barry; FIELD Martha. Economía Ambiental. Mc Graw Hill, Tercera Edición, Madrid, 2003.

- Fundación Para el Desarrollo Sustentable. Esquemas de secuestro de carbono en zonas de pastoreo. [en línea] (2003). [Consultado el 8 de Dic. 2009]. Disponible en: http://www.fundacionsustentable.org/modules.php?name $=$ News\&file= print\&sid $=48$

- HERRADOR Doribel; DIMAS Leopoldo. Valoración económica del agua para el área metropolitana de San Salvador. San Salvador; PRISMA [en línea] 2001. [consultado el 25 de sep 2009]. Disponible en: http://www.bvsde.paho.org/bvsacd/cd57/valoracion_agua.pdf

- HOFSTEDE Robert; MENA Patricio. Los Beneficios Escondidos del Páramo: servicios ecológicos e impacto humano. Proyecto Páramo (EcoCiencia, Instituto de Montaña, Universidad de Amnsterdam. Isla Fernandina N43-41 y T de Berlanga. [en linea] [consultado el 17 de Nov. Del 2009]. Disponible en: 
http://www.condesan.org/e-foros/Bishkek/Bishkek\%20B1-Caso(R.HofstedeP.Mena).htm

- HYPERGEO. Balance Hídrico. 2004 [En línea] [consultado el 20 Sep. 2009] Disponible en: http://www.hypergeo.eu/spip.php?article300

- JACOBS, Michael. Economía Verde: Medio ambiente y desarrollo sostenible. Tercer mundo editores y ediciones unidas Bogota, 1995.

- $\quad$ MARTINEZ Miguel; KOSOY Nicolás. Compensaciones monetarias y conservación de bosques, Pagos por servicios ambientales y pobreza en una comunidad rural en Honduras. En: Revista de la Red Iberoamericana de Economía Ecológica [en línea]. Vol. 6, No. 40 50(2007) [consultado 28 Feb. 2009] Disponible en http://www.redibec.org/IVO/rev6_03.pdf

- $\quad$ MARTINO, Daniel L.; VAN HOFF, Eduardo. Mercado del Carbono: una oportunidad para Uruguay. [en línea] Artículo publicado en Uruguay Forestal (21:4-9) [Consultado el 08 Nov. 2009]. Disponible en: http://www.inia.org.uy/disciplinas/agroclima/ambiente/carbono.html

- MARQUEZ Manrique, Maritza. Plan Maestro de Acueducto. Empopamplona S.A.E.S.P. 2006

- NAVAS Peñaranda, Yesid; ALVARES Vargas, Janeth; OCHOA Uribe Adolfo; PULIDO Acevedo Rubier. Reglamentación del uso del agua en las microcuencas del Volcán y Monteadentro Municipio de Pamplona Departamento de Norte de Santander. Corporación Autónoma Regional de la Frontera "CORPONOR". Pamplona 2004.

- PBOT. Plan Básico de Ordenamiento territorial. Pamplona 2001. Alcaldía de Pamplona

- Plan de administración y manejo ambiental para el área estratégica parte alta de la microcuenca el Volcán municipio de Pamplona. Bogota, 2005, Universidad Distrital Francisco José de Caldas-CORPONOR. proyecto curricular de ingeniería forestal.

- Republica de Colombia, Ministerio del Medio Ambiente, Vivienda y Desarrollo Territorial, Sistema Nacional Ambiental (SINA). Resolución 0011del 9 de Marzo del 2004.

- ROJAS Padilla, J. PEREZ Rincón, M. y PEÑA Varón, M, 2001. La valoración contingente: una alternativa para determinar la viabilidad financiera de proyectos de tratamiento de aguas residuales en zonas rurales de países tropicales. [En línea] (2001). [consultado el 3 Nov. 2009]. Disponible en: http://objetos.univalle.edu.co/files/La_valoración _contingente.pdf

- SAMUELSON. NORDHAUS. Economía. Mc Graw Hill, Decimoséptima edición. Madrid España, 2002.

- World Health Organization. Indoor air pollution and health. En: Fact sheet $\mathrm{N}^{\circ} 292$ June 2005 [en línea] (2005) [consultado 4 Nov. 2009] Disponible en: http://www.who.int/mediacentre/factsheets/fs292/en/index.html

- SACHS, Jefrey. 2008. Economía para un planeta abarrotado. Primera edición. Bogotá D.C.

- SÁNCHEZ Karla; JIMÉNEZ Francisco; VELÁSQUEZ Sergio; PIEDRA Mario; ROMERO Eddy. Metodología de análisis multicriterio para la identificación de áreas prioritarias de manejo del recurso hídrico en la cuenca Río Sarapiqui, Costa Rica. En Recursos Naturales y Ambientales [En línea] (2004) [consultado 11 May. 2009]. Disponible en: http://ciat-library-ciat-cgiar.org/articulos_ciat/karla1.pdf 
- Soluciones para un mundo mejor (2009). [en línea] [consultado el 8 de Dic. 2009].

Disponible en: http://www.co2-

solutions.com/menu_web/index_menu.asp?cuerpo=normalsec.asp\&id_sec $=628 \& \mathrm{i}$ d_web=1

- $\quad$ STIGLITZ Joseph, Economía del sector Publico. 2 edición. Antoni Bosch Editor.

\section{ANEXOS}

\section{ENCUESTA PARA LA VALORACIÓN MONETARIA DE LOS BENEFICIOS QUE PUEDE RENDIR UN USO ÓPTIMO DEL SUELO EN LA MICROCUENCA DE MONTEADENTRO DEL RIO PAMPLONITA, PAMPLONA, N.S. PRIMERA PARTE}

El soporte de vida del planeta esta vinculado al buen funcionamiento de los ecosistemas, la base de producción primaria esta integrada por el agua y el suelo, la intervención del hombre en áreas estratégicas como los nacimientos de los ríos causa daños en la producción y calidad de agua.

El Río Pamplonita nace a 3.500 m.s.n.m. y esta encargado de suplir la demanda de agua de los habitantes de la ciudad de Pamplona. Este lo conforman las nacientes que se encuentran en las microcuencas de Monteadentro y El Volcán. En la actualidad la microcuenca el Volcán se encuentra reforestada y a cargo de CORPONOR dentro del Plan de Administración y Manejo Ambiental, sin embargo la microcuenca de Monteadentro es propiedad de diferentes dueños que utilizan sus suelos para siembra y ganadería. Para garantizar el suministro de agua durante los próximos años y evitar posibles costos futuros en proyectos como la construcción de una represa o lago superficial en el municipio de Pamplona se hace necesario proteger las áreas estratégicas de la microcuenca de Monteadentro.

\begin{tabular}{|c|c|}
\hline $\begin{array}{l}\text { DAÑOS A LA MICROCUENCA DE } \\
\text { MONTEADENTRO EN MANOS DE } \\
\text { PROPIEDAD PRIVADA }\end{array}$ & $\begin{array}{c}\text { BENEFICIOS DE LA MICROCUENCA } \\
\text { MONTEADENTRO DENTRO DE UN PLAN } \\
\text { DE ADMINISTRACION Y MANEJO } \\
\text { AMBIENTAL }\end{array}$ \\
\hline $\begin{array}{l}\text { - La ausencia de vegetación boscosa por el uso de } \\
\text { suelos para siembra y ganadería disminuye la } \\
\text { producción de agua por falta de ramas, troncos y } \\
\text { raíces que intercepten, condensen y almacenen el } \\
\text { agua. Esto provoca: } \\
\text { 1. Disminución de agua para el riego de cultivos en } \\
\text { la parte baja de la microcuenca y consumo } \\
\text { humano en la actualidad, además según } \\
\text { proyecciones hechas, incapacidad de suplir la } \\
\text { demanda de agua para el año } 2015 \text {. } \\
\text { 2. Contaminación del agua que capta el acueducto } \\
\text { por el uso de agroquímicos para siembra, } \\
\text { estiércol del ganado y descargas residuales } \\
\text { domesticas. }\end{array}$ & $\begin{array}{l}\text { - Reforestación para mejorar la capacidad de } \\
\text { intercepción, condensación y almacenamiento } \\
\text { de agua. } \\
\text { - Mejora en la calidad de agua por la eliminación } \\
\text { de agroquímicos, estiércol y desechos } \\
\text { humanos. } \\
\text { - Mayor estabilidad en los caudales y eventual } \\
\text { aumento de estos para el riego de los cultivos } \\
\text { de la parte baja de la microcuenca y el } \\
\text { consumo humano del municipio de Pamplona. }\end{array}$ \\
\hline
\end{tabular}




\section{SEGUNDA PARTE}

1. ¿Estaría Ud. dispuesto a pagar una suma mensual durante un año, con el fin de que se compren las áreas estratégicas de la Microcuenca de Monteadentro, se reforesten y se protejan los bosques y ecosistemas de estas áreas, y de esta manera asegurar el suministro de agua proveniente de la microcuenca de Monteadentro para su familia?

2.¿cuánto estaría dispuesto a pagar? pesos mensuales durante un año en su factura de acueducto y alcantarillado.

La compra de las áreas estratégicas para reforestación y conservación presta unos servicios ambientales diferentes a la producción y calidad de agua. Estos servicios son: hábitat de 393 especies de flora y fauna, oxigeno y almacenamiento de carbono útil para mitigar los daños causados por los gases de efecto invernadero como el calentamiento global y brindan belleza escénica.

3. ¿Estaría dispuesto a pagar mas de esta cantidad porque además valora el conjunto total de servicios que provee esta microcuenca?

4. ¿cuánto estaría dispuesto a pagar de más? pesos mensuales durante un año en su factura de acueducto y alcantarillado.

\section{TERCERA PARTE}

1. Sexo

2. Edad

\section{Ocupación en el ultimo mes}

\begin{tabular}{|l|l|l|l|l}
\hline a. Sin actividad & $\begin{array}{l}\text { b. Trabajador } \\
\text { independiente }\end{array}$ & $\begin{array}{l}\text { c. } \\
\text { Empleado }\end{array}$ & d. Pensionado o jubilado & g. Estudiante \\
\hline
\end{tabular}

\section{Nivel de educación:}

\begin{tabular}{|l|l|l|l|l|l|l|}
\hline a. Ninguno( ) & b. Primaria ( ) & c. Secundaria ( ) & d. Técnico ( ) & d. Pregrado ( ) & \multicolumn{2}{|l|}{ e. Postgrado ( ) } \\
\hline 5. Estado civil & a. Soltero ( ) & b. Casado ( ) & c. Separado ( ) & d. Unión libre ( ) & e. Viudo ( ) \\
\hline
\end{tabular}

6. ¿cuántas personas habitan su vivienda o hacen uso del establecimiento?

\begin{tabular}{|c|c|c|c|c|c|}
\hline \multicolumn{3}{|c|}{ 7. Su residencia en Pamplona es } & \multicolumn{2}{|c|}{ a. Permanente } & b. Temporal \\
\hline \multicolumn{6}{|c|}{ 8. Usuario } \\
\hline a. Estrato 1 & b. Estrato 2 & c. Estrato 3 & d. Estrato 4 & $\begin{array}{l}\text { e. Comercial e } \\
\text { industrial }\end{array}$ & $\begin{array}{l}\text { f. Especial u } \\
\text { oficial }\end{array}$ \\
\hline
\end{tabular}


VALORACIÓN MONETARIA DE LOS BENEFICIOS

QUE PUEDE RENDIR UN USO ÓPTIMO DEL SUELO

EN LA MICROCUENCA MONTEADENTRO DEL RIO

PAMPLONITA, PAMPLONA, N. DE S.

\section{MODELO}

Dependent Variable: DAP

Method: ML - Binary Probit (Quadratic hill climbing)

Date: 11/23/09 Time: 23:27

Sample: 195

Included observations: 95

Convergence achieved after 4 iterations

Covariance matrix computed using second derivatives

\begin{tabular}{|c|c|c|c|c|}
\hline Variable & Coefficient & Std. Error & z-Statistic & Prob. \\
\hline $\mathrm{C}$ & 0.899499 & 1.421921 & 0.632594 & 0.5270 \\
\hline GENERO & 0.160066 & 0.339457 & 0.471536 & 0.6373 \\
\hline EDAD & -0.215926 & 0.205277 & -1.051874 & 0.2929 \\
\hline OCUPACION & 0.094665 & 0.124522 & 0.760231 & 0.4471 \\
\hline EDUCACION & 0.039736 & 0.151909 & 0.261578 & 0.7936 \\
\hline CIVIL & -0.248149 & 0.290825 & -0.853260 & 0.3935 \\
\hline INGRESO & 0.126146 & 0.173029 & 0.729047 & 0.4660 \\
\hline $\mathrm{PF}$ & 0.527165 & 0.449406 & 1.173027 & 0.2408 \\
\hline RESIDENTES & -0.120249 & 0.067074 & -1.792770 & 0.0730 \\
\hline Mean dependent var & \multicolumn{3}{|c|}{0.778947 S.D. dependent var } & 0.417157 \\
\hline S.E. of regression & \multicolumn{3}{|c|}{0.406562 Akaike info criterion } & 1.108793 \\
\hline Sum squared resid & \multicolumn{3}{|l|}{14.21517} & 1.350740 \\
\hline Log likelihood & -43.66768 & \multicolumn{2}{|c|}{ Hannan-Quinn criter. } & 1.206558 \\
\hline Restr. log likelihood & -50.18252 & \multicolumn{2}{|c|}{ Avg. log likelihood } & -0.459660 \\
\hline LR statistic (8 df) & 13.02966 & \multicolumn{2}{|c|}{ McFadden R-squared } & 0.129823 \\
\hline Probability(LR stat) & 0.110833 & & & \\
\hline Obs with Dep $=0$ & 21 & Total obs & & 95 \\
\hline Obs with Dep $=1$ & 74 & & & \\
\hline
\end{tabular}

